\title{
Analysis of Overhead Costs Management in Companies
}

Wolfram Irsa, Csaba Székely

University of Sopron, István Széchenyi Economics and Management Doctoral School, Hungary

\section{Abstract}

The development of overhead costs management is becoming more and more important as the percentage of overhead costs is rising. The last 15 years have demonstrated the awakening of advanced methods and tools aimed at understanding the utilization of overheads better. The paper investigates the current state of overhead costs management using a sample of 20 companies in Austria, Hungary, and Slovakia. A qualitative approach was applied in a multi-case study, which unveiled the significance of overhead cost management with the increasing trend of importance. The effort reflects current innovations using digitalization of processes. The findings show that (1) the majority of the companies indicated that digitalization heavily impacts overhead costs; (2) all expressed their dissatisfaction with the tools currently used; and (3) the majority cited that usability and speed are the predominant factors. The analysis and the subsequent synthesis delivered three theses: (1) perception that digital competence enables overhead costs management; (2) belief that competencies are insufficient; and (3) there are prerequisites for success in overhead costs management. The paper examines the situation in seven industries represented in the sectors of manufacturing and transportation/storage for the time period from 2008 to 2017. The paper concludes with several recommendations for academia, businesses, and future research.

Keywords: digitalization, organizational behaviour, overhead-costs management JEL classification: D23, O14, O33

Acknowledgements: I thank wholeheartedly the two anonymous reviewers who gave me priceless feedback for further improvement. I am indebted to Professor Irena Zvarl from the University of Applied Sciences Burgenland in Eisenstadt, Austria and Professor Csaba Székely from the University of Sopron, Hungary. - Both have guided me throughout my academic career. Furthermore, I thank the IRSA Family fund for sponsoring my scientific work.

Paper type: Research article

Received: Mar 6, 2021

Accepted: May 27, 2021

DOI: $10.54820 /$ ZZRU4894 


\section{Introduction}

This paper seeks to explore the phenomenon of how businesses deal with the increasing importance of overhead costs management in the advent of innovations driven by digitalization. Digitalization is the process of employing digital information and technologies in order to transform them into business operations. It is the use of digital technologies to potentially change a business model and provide new revenue and value producing opportunities. Conversely, digitization is the process of changing from analog form to digital; it refers to taking analog information and encoding it into zeroes and ones so that computers can store, process, and transmit information.

The purpose of the paper is to explore with a sample of companies their perceptions of and why they believe that overhead costs management is important and how they successfully manage the development of overhead costs, triggered by the innovations of digitalization. It was anticipated that the knowledge generated from this inquiry would create new insights and so inform the academic community and business leaders on the impact of contemporary capabilities.

The paper employs qualitative multi-case study methodology with quantitative statistical description to portray the phenomenon under investigation. Participants of the paper included a purposefully selected group consisting of 20 companies from seven different industries (i.e., automotive components, automotive OEM, aviation, beverage, chemicals, transportation, steel). The companies reside in Austria, Hungary, and Slovakia; all had an impressive economical track record as world market leaders in their fields. The participants had at least 10 years of experience in the industry and held management responsibilities; they consisted of seven females and 13 male participants from 27 to 54 years old. The educational level ranged from PhD to technician.

The paper contributes to the scientific research of contemporary overhead cost management. The next section explains the research topic, followed by the sections methodology, results, discussion, and conclusion. A comprehensive bibliography serves as references.

\section{Background}

Cost management has always been important for companies (Loy et al., 2018). Since the financial crisis in the year 2008, which turned into an economic crisis for many companies, the successful management of costs became even more important (Pianta et al., 2019). The overhead costs, which are mostly fixed costs from a structural point of view and indirect costs from an accounting point of view, become more significant due to several reasons (Novák et al., 2017). There is the issue of inflexibility of scaling overheads quickly up and down as required in dynamic markets. Further, the reduction of overhead is a delicate process as it often means reducing the headcount (Alix Partners, 2013). Even if lay-offs can be avoided, the reduction of overhead costs is a significant change which means abandoning wellestablished routines (e.g., so far unaccounted services need then a precise recording of the service to a sellable cost object).

The continuing surge of overhead is immanent due to the ongoing automation of business processes. Miller et al. (1985) presented an increase of overhead from $50 \%$ in the middle of the 19th century to roughly $85 \% 190$ years later as a percentage of value added. The data stem from the North American Manufacturing Futures Survey and used as a research method a survey with more than 200 respondents from just as many different business units; the typical job description of the respondents was 
vice president of operations. The survey was repeated in the subsequent years with respondents from Asia and Europe, which supported the original results. The scientific value of the survey appears questionable as there is ambiguity within the understanding of the term overhead over such a long period of time. Nevertheless, the survey and the publication disclosed for the first time the long-term dynamics of the topic and stimulated awareness for systematic research. As of now, the trend indicates that overhead will still continue to slightly rise. Consequently, the direct labor will decrease. The paper seeks to bolster the understanding of the survey with qualitative and quantitative research methods.

\section{Research objective}

Research indicates that a compelling number of businesses are wondering how the changing environment caused by digitalization in the last years will impact their capability to successfully manage overhead costs. Hence, despite their fortunate past and their serious investment of time and money to understand upcoming innovations, these businesses face uncertainty concerning their future existence. In fact, uncertainty is just one element of four, which are known as VUCA (HernándezSantibáñez et al., 2019). VUCA stands for volatility, uncertainty, complexity, ambiguity and describes the dynamics in digitalized markets. There is little information about how to successfully handle this phenomenon.

\section{Research questions}

The purpose of the paper was to explore with 20 businesses their perceptions of how they manage overhead costs in the advent of business processes digitalization. It is anticipated that more informed decisions could be made by current businesses, academic scholars, and prospective business founders based upon the results of this study. The paper should enable a better understanding of the needs of the businesses, the challenges and issues they face, and the academic foundation based on theories and concepts. To shed light on the problem, the following research questions were addressed:

1. How does the digitalization of processes impact the management of overhead costs?

2. What are the

of the current approaches of the management of overhead costs in respect to methods and tools? If there are limitations, what can be done to overcome them?

3. In general, what are the prerequisites for the successful management of overhead costs?

Each research question (RQ) stands independently for itself. Nevertheless, there are links between them. In order to first understand the ramifications, it makes sense to place the first $R Q$ at the top of the list. Following, the second $R Q$ addresses the internal details. Finally, the third $R Q$ asks for overall prerequisites in order to succeed in the field of overhead costs management, which offers a universal perspective.

\section{Unit of analysis}

The paper used unit of analysis to design the data gathering from the informants (i.e. unit of observation) and to measure concepts within the subject matter. The unit of analysis specifies the research object concerning the level of investigation and the specific data. It is the major entity for analyzing the data and composing the synthesis. 
Figure 1

Unit of analysis for the paper
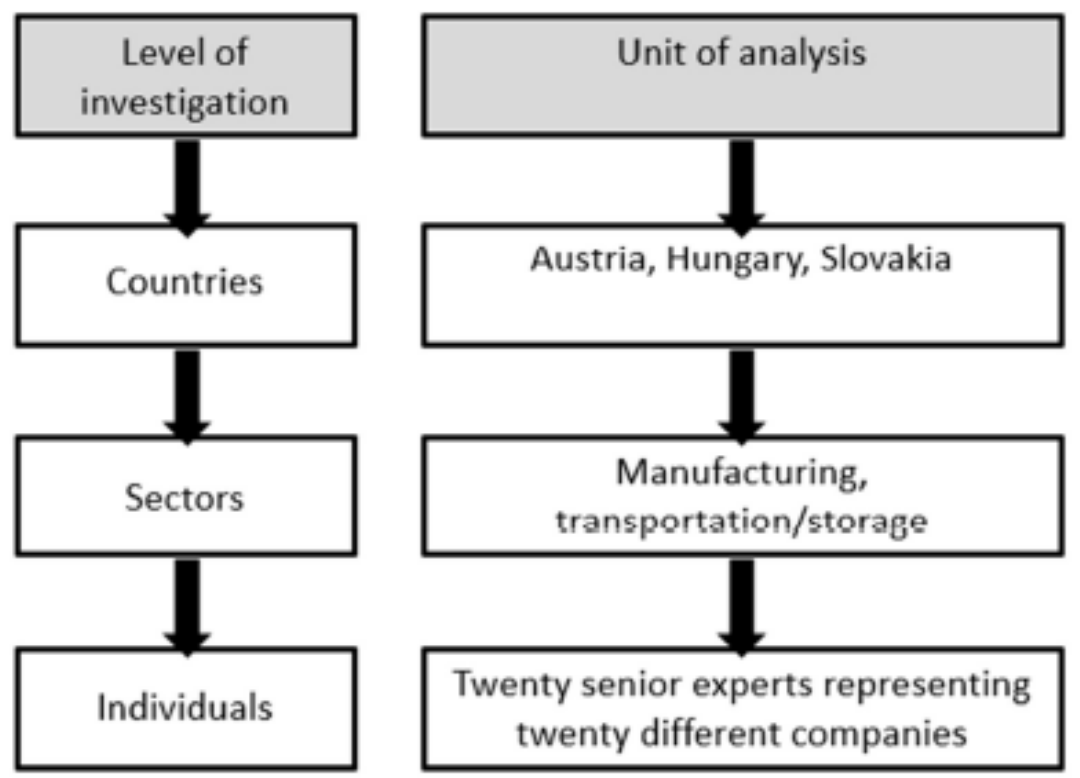

Source: Author's illustration

Figure 1 explains the systematic breakdown of the levels of investigation with the corresponding unit of analysis. It starts at the country level for Austria, Hungary, and Slovakia. The next level is sectors comprising of manufacturing and transportation /storage, which include the before mentioned seven industries; the definition of sectors is important as it used for quantitative triangulation with an external database in the section Results. The bottom level addresses on an individual basis twenty different senior experts from twenty different companies (i.e. unit of observation). Their qualitative views, supported with the quantitative data from their companies, formed the foundation of the paper from an analytical point of view. For the syntheses, the same units of analysis were used.

\section{Methodology}

After a thoroughly literature review, the perceptions and experiences of 20 participants from 20 different enterprises in seven different industries were studied. The participants were drawn from a pool of potential candidates and had successfully demonstrated their capabilities in the industry over a period of 10 to 15 years. They had been challenged with ongoing changes due to digitalization and the impact on overhead costs. The investigation of the paper followed the tradition of a multi-case study using qualitative research methods as well as descriptive statistics using quantitative research methods (Creswell, 2014; Masud, 2018).

In-depth expert interviews prepared with a survey were the primary methods of data collection (Friese, 2018). The interview process began with two pilot interviews. After fine-tuning the process and procedures, the information gathering began. The information - collected by means of 20 individual interviews and a focus group meeting - consequently formed the foundation for the overall findings of the paper. A pseudonym identified each interviewee with a participant code; all interviews and focus group statements were recorded and transcribed word for word. Further, the participants completed critical incident reports in order to root the findings emanating from the in-depth expert interviews in a practical context, rich with 
specifics. The answers were safe guarded with quantitative statistical analysis based on the survey using Likert scales. In order to challenge the results in a broader context, an income statement analysis using data from the enterprises and the BACH database (Bank for the Accounts of Companies Harmonized) from the European Union was performed.

In summary, as research methodology quantitative and qualitative case study methodology was employed to illustrate the phenomenon of how businesses deal with the digitalization of processes with respect to overhead costs, the limitations of the current approaches and what the success factors in managing overhead costs successfully are. The sample of participants consisted of 20 purposefully selected individuals. Four data collection methods were employed, namely surveys (quantitative and qualitative), individual interviews (qualitative), critical incidents (qualitative), and focus group (qualitative). The data were challenged with literature, other data bases and the emerging findings. Credibility and dependability were addressed by carefully selected strategies, in particular triangulation of sources and methods.

\section{Results}

The purpose of the multi-case study in the paper was to explore, by means of a sample of businesses, the perceptions of how the digitalization of processes impacts the management of overhead costs.

Figure 2

Overhead in percent of total expense

\section{Overhead-costs in \% of total expense}

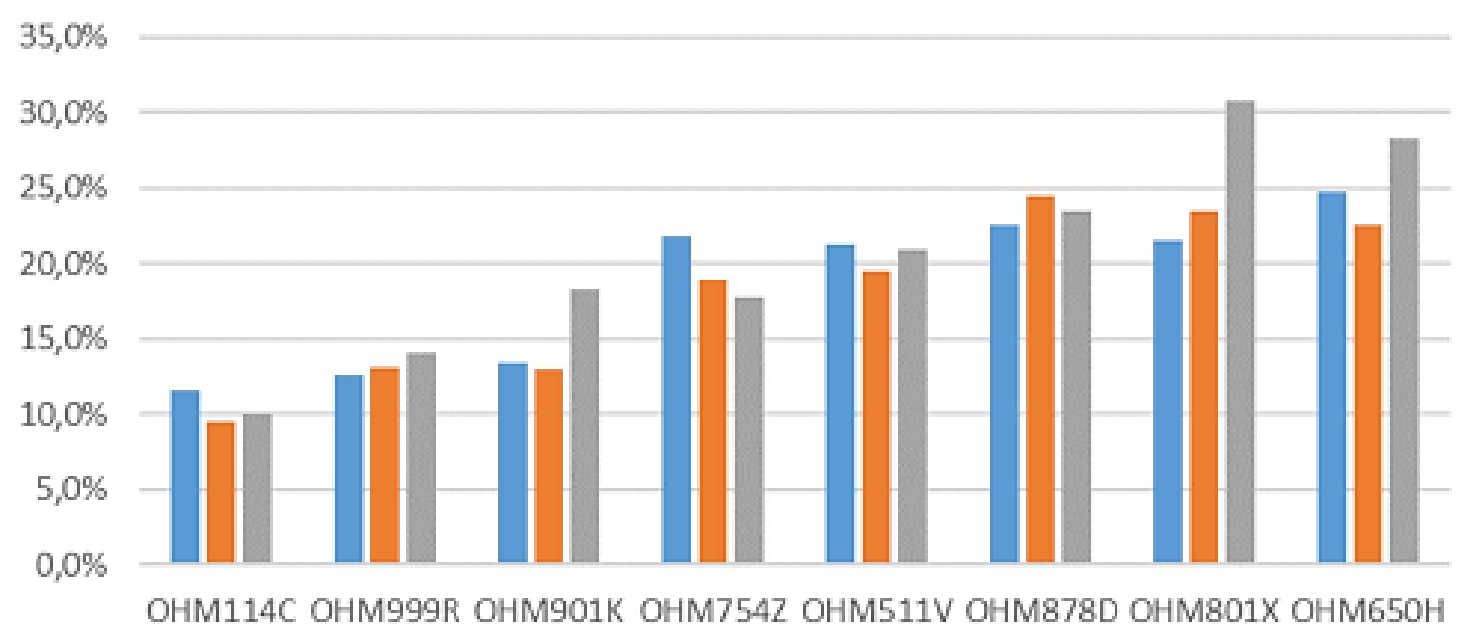

불 $2008=2013=2017$

Source: Author's illustration

Figure 2 shows for the selected enterprises (represented anonymously by the code on the abscissa) the overhead costs for the years 2008, 2013, and 2017. It used the assumption that the expenses above the gross margin line were all direct costs without overhead, called Cost-of-Goods-Sold (COGS). The remaining cost entities before the operating income were identified as overhead-costs. This was not precisely true as the analysis made apparent, but it gave a first insight into the 
operational strategy of the enterprise in terms of which expenses were reported as an isolated line-item. Further, and this is the core value of the analysis, it showed the dynamics over time for the specific enterprise over a 10-year period. The data was collected from their income statements of the official annual reports. The reported years were chosen intentionally in order to be consistent with the analysis based on the available data of the BACH database (BACH Working Group, 2019). The BACH database systems of ECCBSO (www.eccbso.org) contains historical income statement data that goes back to 2001. To satisfy the research purpose, data of the years 2008, 2013, and 2017 were selected, specifically COGS and Overhead, in total and in percentage to total expenses.

Figure 3

Manufacturing in Austria: COGS and overhead for 2008, 2013, and 2017

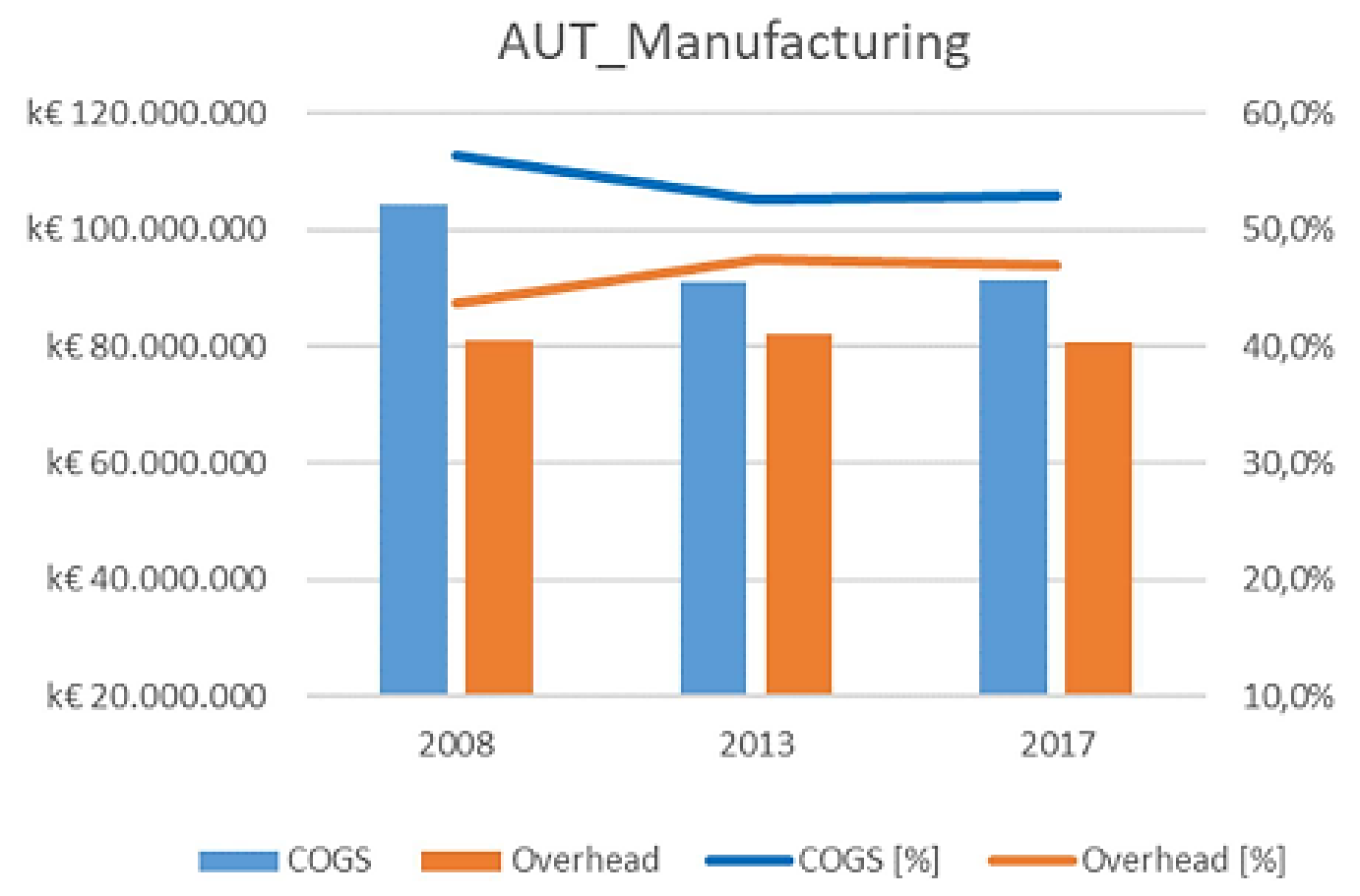

Source: BACH Working Group (2019)

Figure 3 shows the dynamics of overhead over time in the sector manufacturing in Austria with three datapoints for the period 2008 to 2017. In 2008, overhead of $€ 81 \mathrm{~b}$ was reported, representing $43.7 \%$ of the total expenses. The percentage increases to $47.5 \%$ for 2013 and remains at $47 \%$ for 2017 . There is an increasing trend for the sector manufacturing. For Slovakia data was available in BACH database (unfortunately not for Hungary) as well. For Slovakia $n$ 2008, overhead of $€ 17.2 \mathrm{~b}$ was reported, representing $35.8 \%$ of the total expenses. The percentage decreases slightly to $34.2 \%$ for 2013 and rises to $38.6 \%$ for 2017. The total numbers for 2017 are diluted as the Slovakian Ministry of Finance reported data of 2.620 firms in 2017 compared to 11.652 firms in 2013. Nevertheless, based on percentage, there is an increasing trend for the sector manufacturing. 
Table 1

Findings, interpretations, and conclusions

\begin{tabular}{|c|c|c|}
\hline Findings & Interpretations & Conclusions \\
\hline $\begin{array}{l}\text { Finding 1: } \\
\text { A majority of } \\
\text { participants indicated } \\
\text { that digitalization } \\
\text { impacts heavily the } \\
\text { overhead. }\end{array}$ & $\begin{array}{l}\text { - Overhead costs } \\
\text { management are a 'hot' } \\
\text { topic. } \\
\text { - There is a long-term trend } \\
\text { from the past that seems } \\
\text { to continue into the } \\
\text { future. } \\
\text { - There are unrealistic } \\
\text { expectations. } \\
\text { - Individual idiosyncrasies } \\
\text { are part of the subject } \\
\text { matter. }\end{array}$ & $\begin{array}{l}\text { Professionals who deal with } \\
\text { overhead should not expect that } \\
\text { there is a magical equation that } \\
\text { solves all problems. Overhead } \\
\text { costs management has always } \\
\text { been difficult; digitalization does } \\
\text { not make it easier. The primary } \\
\text { purpose of overhead costs } \\
\text { management is to assign indirect } \\
\text { costs to cost objects. The bigger } \\
\text { the overhead, the more precision } \\
\text { is requested. }\end{array}$ \\
\hline $\begin{array}{l}\text { Finding 2: } \\
\text { All participants } \\
\text { expressed their } \\
\text { dissatisfaction with the } \\
\text { currently used tools. The } \\
\text { limitations are mainly } \\
\text { inflexibility and lack of } \\
\text { knowledge. }\end{array}$ & $\begin{array}{l}\text { - Tools are used because of } \\
\text { historical reasons. } \\
\text { - There was no effort to re- } \\
\text { evaluate the situations. } \\
\text { - There are unrealistic } \\
\text { expectations. } \\
\text { - A lack of understanding } \\
\text { inflates the problem. }\end{array}$ & $\begin{array}{l}\text { Digitalization is another parameter } \\
\text { that makes the equation even } \\
\text { more complex. Being grounded in } \\
\text { practice alone is insufficient. } \\
\text { Enterprises need theoretical know- } \\
\text { how, and they should acquire this } \\
\text { through more formal education. In } \\
\text { the absence of formal } \\
\text { preparation, enterprises need to } \\
\text { be open to new ways of learning. }\end{array}$ \\
\hline $\begin{array}{l}\text { Finding 3: } \\
\text { The majority of } \\
\text { participants cited that } \\
\text { usability and speed are } \\
\text { the predominant } \\
\text { factors. More than half } \\
\text { indicated that } \\
\text { transparency of } \\
\text { overhead is } \\
\text { instrumental. }\end{array}$ & $\begin{array}{l}\text { - Twelve different factors } \\
\text { were called, but there are } \\
\text { three favorites. } \\
\text { - The dynamics of markets } \\
\text { (VUCA) essentially dictate } \\
\text { the factors. } \\
\text { - There is an eager interest } \\
\text { to find better solutions. } \\
\text { - The requirements are } \\
\text { clearly stated and } \\
\text { understood. }\end{array}$ & $\begin{array}{l}\text { Dialogue with enterprises in the } \\
\text { demonstrated setting can provide } \\
\text { a source of information and } \\
\text { support. It offers room for reflection } \\
\text { and aligned action. Collaboration } \\
\text { offers opportunities for } \\
\text { development of new } \\
\text { understanding and new learning. } \\
\text { Progress also is largely a function } \\
\text { of personal conduct as well as } \\
\text { motivation and drive. The } \\
\text { experience calls for collaboration. }\end{array}$ \\
\hline
\end{tabular}

Note: Any comments to the table

Source: Own research

The conclusions presented in Table 1 address the three the research questions. The answers postulate three hypotheses: (1) Innovation (e.g., digitalization) drives the percentage of overhead costs continuously upwards; (2) The surge of digitalization has an impact on related methods and tools; and (3) Digitalized services have a direct effect on overhead costs. It points out a new scientific contribution for the identified unit of analysis and leads to the conclusion at the end of the paper.

\section{Discussion}

The hypotheses were based on the findings from the qualitative data, the quantitative data of the income statements, and the research problem. The three hypotheses identified are discussed next in respect to the analysis and synthesis of the paper's results.

Figure 4

Synthesis of hypotheses, findings, and entities 


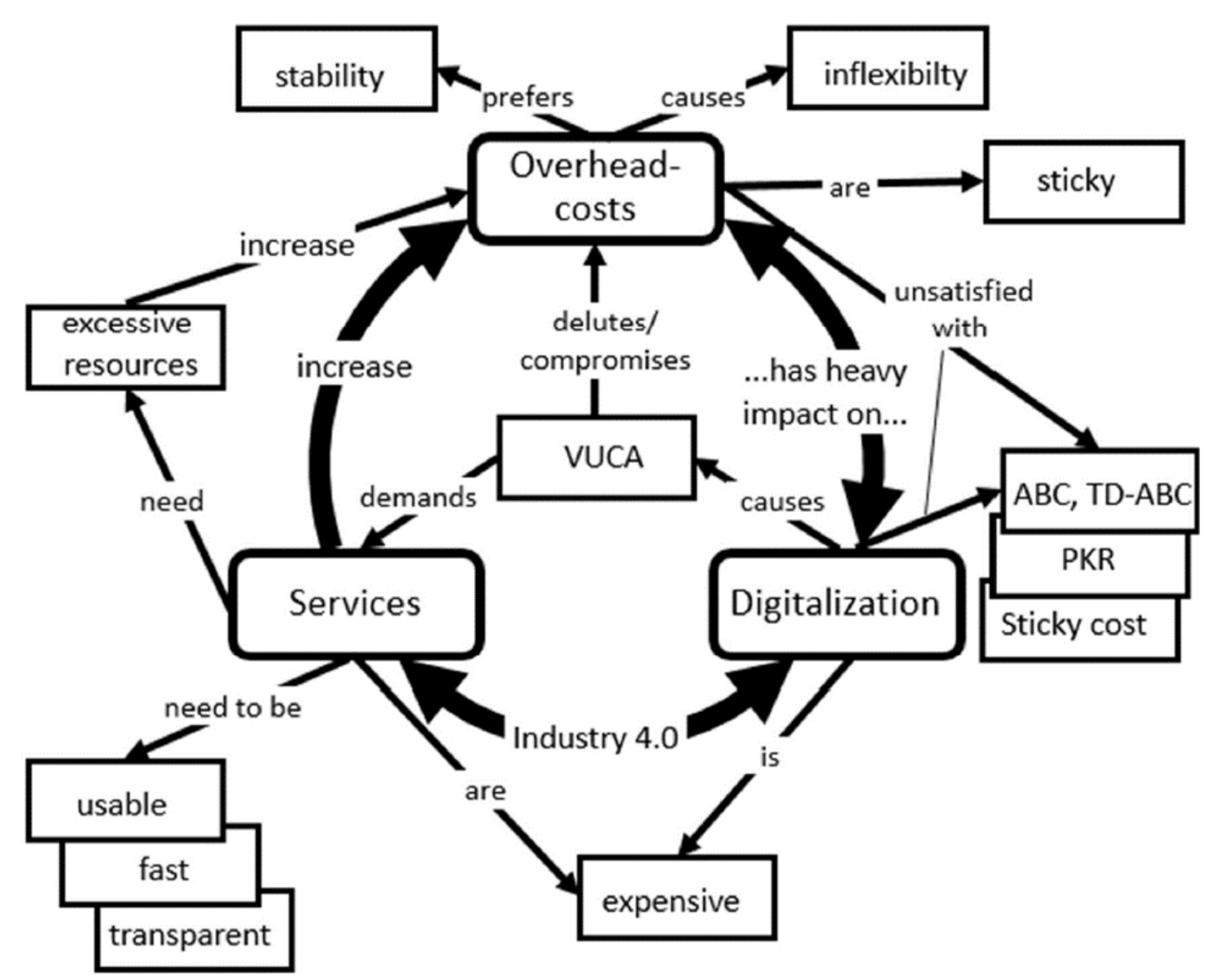

Source: Author's illustration

Figure 4 depicts the synthesis of the research work; based on hypotheses, the findings, and the entities mentioned during qualitative research they are incorporated in the figure above.

The first hypothesis underlying the research was that innovation (e.g., digitalization) drives the percentage of overhead continuously upwards. This hypothesis held true according to the first finding. The sample of enterprises in this paper expressly stated that the digitalization increases the percentage of overhead.

The second hypothesis was that the surge of digitalization has an impact on related methods and tools. This hypothesis turned out to be true. Initially, enterprises appeared to be dependent on Industry 4.0 technologies. Although, contrary to the original belief, the businesses first need a compelling use case in order to advance with related services. In addition, the application of the right methods and tools is needed in order to track and control the overhead. This notion was illustrated in the second finding of the research.

The third hypothesis was that digitalized services have a direct effect on overhead costs. This hypothesis held true as well. The reason is that it needs a bypass through (often expensive) resources in order to perform the services. These resources are indirect costs and therefore overhead costs. The characteristics of suitable processes dealing with digitalization are usability, speed, and transparency. They are dictated by VUCA business environments.

Volatile situations, lack of certainty about future revenue streams, complex highly interdependent processes, and ambiguous interpretations are not necessarily a stringent predictor of increasing overhead costs per se. It is true that the entire cost of the service can be directly associated to the sellable product, then it becomes 
direct cost. Nevertheless, it is only theoretically possible in very rare cases (e.g., a dedicated salesperson that serves only one customer), in the multi-case study at hand it was not mentioned a single time. In fact, when asked about dedicated resources for easy cost assignment, it was denied. The requirements are user-friendly, fast, and transparent services, which are delivered multi-dimensionally with great flexibility over a broad customer basis. It had been the quintessence illustrated in the third finding.

Because the analysis conclusively depends on the choices and thinking of the researcher, qualitative studies in general have constraints relating to the researcher's subjectivity. Quantitative studies are hampered by the improper representation of the target population, the inability to control the environment, and the difficulty in telling data analysis. A dominating concern is the bias of the researcher; it frames the assumptions, interests, needs and perceptions. The pivotal constraint of the paper at hand is the issue of my subjectivity and the potential bias due to my participation in conducting the research. My personal experience in the industry with the subject matter certainly contains a set of opinions which I needed to set strictly aside. Related to that may have been the difficulty of the interviewees to adjust to the researcher transforming into the role of the interviewer, a phenomenon referred to by Maxwell (2013) as participant reactivity. Because some of the participants knew me already, their responses may have been affected and influenced. They could have tried to fraternize with me by offering responses they perceived I was looking for or they thought I would perceive as helpful. In contrast, it would be possible that because of the personal acquaintance, these few participants could have held back and been less candid in the discussions; however, this did not take place as proven by the very active discussions. Recognizing these constraints, I took the following measures. First, I acknowledged my potentially biased agenda and stated my assumptions up front. Second, the coding schema with the legend was scrutinized by peer review; the same took place with the transcripts and coded interviews. Finally, to mitigate the constraints during data analysis and synthesis, I removed all participant names and used only the participant code. Further, a broader basis of data-more sectors, different regions - would be helpful.

\section{Conclusion}

The development of overhead costs management is becoming more and more important as the percentage of overhead costs on the overall costs is constantly rising. The last 15 years have demonstrated the awakening of several advanced methods and tools for overhead costs management. They have in common the notion of understanding the utilization of overhead better. This paper investigated the current state of overhead costs management with a sample of 20 companies in Austria, Hungary, and Slovakia. A qualitative approach was applied in a multi-case study, which unveiled the significance of overhead costs management with the increasing trend of importance. The findings were supported by quantitative analysis, within the samples, income statements, and external data. The effort reflected current innovations using the digitalization of processes. The findings showed that (1) the majority of the companies indicated that digitalization heavily impacts overhead costs; (2) all expressed their dissatisfaction with the tools currently used; and (3) the majority cited that usability and speed are the predominant factors for successful overhead costs management. The findings were challenged against the BACH database system of the European Committee of Central Balance Sheet Data Offices. It embedded the findings of the sample into a broader context of the countrywide database by identifying overhead as an imprecise term. The analysis 
and the subsequent synthesis conclude to three theses: (1) the perception that digital competence enables overhead costs management; (2) the persuasion that competencies are insufficient; and (3) there are prerequisites for success in overhead costs management, primarily usability and speed. The scientific novelty of the paper lies in the first qualitative research of the overhead costs situation in the sectors manufacturing and transportation/storage with companies in Austria, Hungary, and Slovakia for the time-period of 2008 to 2017.

The limitation of the study is the small sample size of 20 participants from seven industries. I recommend for further research to be conducted by developing a larger database of information. This would provide a more comprehensive understanding beyond the set-up of this paper. It should further develop a platform as to why some enterprises succeed in managing overhead costs and how they are doing it. The $\mathrm{BACH}$ database system of ECCBSO offers plenty of data, currently containing detailed information from eleven countries in the European Union. For further research directions a broader database covering more sectors and expanding the survey to different regions in the world is proposed.

\section{References}

1. Alix Partners (2013), "Five Steps to Sustainable Overhead Cost Management", available at: https://www.alixpartners.com/insights-impact/insights/five-steps-tosustainable-overhead-cost-management/ (1 st May 2021)

2. BACH Working Group (2019), "The Bank for the Accounts of Companies Harmonized (BACH) database", available at: https://www.ecb.europa.eu/pub/pdf/scpsps/ecbspl 1.en.pdf (1 ${ }^{\text {st }}$ May 2021)

3. Creswell, J. W. (2014). Research Design: qualitative, quantitative, and mixed methods approaches, Sage, Thousand Oaks.

4. Friese, S. (2018), "Grounded Theory Analysis and CAQDAS: A happy pairing or remodeling GT to QDA ?", In Bryant, A., Charmaz, K. (Ed.) The SAGE Handbook of Current Developments in Grounded Theory, Sage, Thousand Oaks, pp. 1-37.

5. Hernández-Santibánezez, N., Mastrolia, T. (2019), "Contract Theory in a VUCA World", SIAM Journal on Control and Optimization, Vol. 57 No. 4, pp. 3072-3100.

6. Loy, T. R., Hartlieb, S. (2018), "Have estimates of cost stickiness changed across listing cohorts?", Journal of Management Control, Vol. 29, pp. 161-181.

7. Masud, M. (2018), "An Examination of Case Studies in Management Research: A Paradigmatic Bridge", International Journal of Social Science Studies, Vol. 6 No. 3, pp. 9-19.

8. Maxwell, J. A. (2013). Qualitative Research Design: An Interactive Approach, Sage, Thousand Oaks.

9. Miller, J. G., Vollmann, T. E. (1985), "The hidden factory - Cutting the explosive growth of overhead costs requires mastery of more than just what happens on the shop floor", available at: https://hbr.org/1985/09/the-hidden-factory (1 ${ }^{\text {st }}$ May 2021)

10. Novák, P., Dvorský, J., Popesko. B., Strouhal, J. (2017), "Analysis of overhead cost behavior: Case study on decision-making approach", Journal of International Studies, Vol. 10 No. 1, pp. 74-91.

11. Pianta, M., Lucchese, M., Nascia, L. (2019), "Reshaping the economy: an industrial and investment policy in Europe", in Gabellini, T., Gasperin, S., Moneta, S. (Eds.), Economic Crisis and Economic Thought: Alternative Theoretical Perspectives on the Economic Crisis, Routlege, London, pp. 260-291. 


\section{About the authors}

Prof. Dr. Dr. h.c. Csaba Székely, D.Sc. has a comprehensive academic career domestically and internationally. He holds degrees in economics and management. He has worked as a university professor at several universities, for the last 15 years at the University of Sopron, Faculty of Economics. He has supervised PhD students for more than 30 years and has chaired many scientific conferences around the world. The author can be contacted at email: ktk.szekely.csaba@gmail.com

Dipl.-Ing. Dr. Wolfram Irsa, CIRM, CFPIM is a PhD graduate student of the University of Sopron, István Széchenyi Economics and Management Doctoral School, Hungary. He has performed studies under the patronage of the International Joint CrossBorder PhD Programme in International Economic Relations and Management at the $\mathrm{FH}$ Burgenland in Austria. He presents at scientific international conferences. The author can be contacted at email: wolfram.irsa@gmail.com 